\title{
Systematic Review \\ The Use of Tranexamic Acid in Anterior Cruciate Ligament Reconstruction: A Systematic Review
}

\author{
Radu Prejbeanu ${ }^{1}$, Mihail Lazar Mioc ${ }^{1, *} \mathbb{1}$, Bogdan Deleanu ${ }^{1}$, Andrei Balanescu ${ }^{2}$, Musab Al Qatawneh ${ }^{2}$ \\ and Daniel Malita ${ }^{1}$ \\ 1 1st Department of Orthopedics and Traumatology, "Victor Babes" University of Medicine and Pharmacy, \\ 300041 Timisoara, Romania; raduprejbeanu@gmail.com (R.P.); bogdandeleanu@yahoo.com (B.D.); \\ d.malita@gmail.com (D.M.) \\ 2 Premiere Hospital, 300643 Timisoara, Romania; andreidan.balanescu@gmail.com (A.B.); \\ msb898@gmail.com (M.A.Q.) \\ * Correspondence: mihail.mioc@umft.ro
}

Citation: Prejbeanu, R.; Mioc, M.L.; Deleanu, B.; Balanescu, A.; Al Qatawneh, M.; Malita, D. The Use of Tranexamic Acid in Anterior Cruciate Ligament Reconstruction: A Systematic Review. Appl. Sci. 2021, 11, 11518. https://doi.org/10.3390/ app112311518

Academic Editor: Claudio Belvedere

Received: 13 November 2021

Accepted: 3 December 2021

Published: 5 December 2021

Publisher's Note: MDPI stays neutral with regard to jurisdictional claims in published maps and institutional affiliations.

Copyright: (c) 2021 by the authors. Licensee MDPI, Basel, Switzerland. This article is an open access article distributed under the terms and conditions of the Creative Commons Attribution (CC BY) license (https:/ / creativecommons.org/licenses/by/ $4.0 /)$.

\begin{abstract}
Background: There are several papers that investigate the use of tranexamic acid (TXA) in anterior cruciate ligament reconstructions (ACLR) or other arthroscopic procedures that show favorable results and little to no complications. We aimed to perform a systematic review of all published randomized controlled trials (RCTs) that wanted to determine the effectiveness of intravenous use of TXA in ACLR. Methods: Data collection was performed independently by two authors via a previously created spreadsheet. They extracted information such as: first author name, publication year, lot size, TXA protocol, surgical protocol, outcome measures and follow-up duration. Results: After applying the screening process and the inclusion criteria, we were left with a total six RCTs. The selected studies included a total of 699 randomized patients. Statistical significance regarding a lower pain score (VAS) in the intervention groups was mostly reported for the early postoperative period ( 2 weeks). A statistically significant decrease in hemarthrosis grade was reported for the first 2-3 weeks. Conclusions: in our study, we show that TXA use in arthroscopic ACLR decreases postoperative blood loss and pain. Some evidence of improvement in functional scores was observed, but we believe that this needs to be addressed in specific long-term result studies.
\end{abstract}

Keywords: tranexamic acid; anterior cruciate ligament reconstruction; postoperative pain; knee hemarthrosis; randomized control trial; knee arthroscopy

\section{Introduction}

One of the most often performed arthroscopic procedures in orthopedic surgery is the anterior cruciate ligament reconstruction (ACLR) while also remaining a low-risk surgical intervention [1]. The number of such procedures is constantly growing due to the predictability of its results and the short recovery period [2,3]. Postoperative pain is usually one of the most common complaints, leading to the delay in recovery and return to activity [4]. One of the pain sources can be excessive knee swelling caused by hemarthrosis. Besides affecting recovery rate, postoperative hemarthrosis can increase infection rates and cause cartilage toxicity [5].

Tranexamic acid (TXA- $\mathrm{C}_{8} \mathrm{H}_{15} \mathrm{NO}_{2}$ ) is a widely used pharmacological agent that prevents needless blood loss in various pathologies [6,7]. TXA acts as an antifibrinolytic agent, stabilizing blood clots and preventing fibrin degradation [8-10]. These usually translate into an enhanced hemostasis, decreased intraoperative bleeding and related complications [11].

There are several papers that investigate the use of TXA in ACLR or other arthroscopic procedures that show favorable results and little to no complications [12-14]. Other recent studies reported conflicting results, showing no difference with using TXA in ACLR $[15,16]$. The contradicting papers and the lack of consensus regarding this matter are characteristics 
of a novelty technique in our specialty field. There have not yet been any recommendations regarding the use of TXA in ACLR in any prestigious guidelines $[17,18]$.

Taking into consideration all the above, the aim of this paper is to perform a systematic review of all published randomized controlled trials (RCTs) that aimed to determine the effectiveness of intravenous use of tranexamic acid (TXA) in anterior cruciate ligament reconstructions (ACLR).

\section{Materials and Methods}

To ensure a transparent and applicable way of presenting our data, we have performed our systematic review in accordance with the Preferred Reporting Items for Systematic reviews and Meta-Analyses (PRISMA) guidelines [19]. The authors of the PRISMA guidelines have updated their methodology in a statement that improves on the previous guideline released in 2009 [20].

\subsection{Eligibility Criteria}

The inclusion criteria we established were as follows: clinical studies that compared TXA with non TXA use in ACLR, randomized control trials (RCTs), a follow-up of at least 4 weeks, studies assessing at least two outcome variables (not only subjective scoring such as pain score) such as knee range of motion (ROM), knee functional scores, hemarthrosis score, knee circumference and drainage volume. Our systematic review did not include other reviews, animal studies, case reports/case series, letter to editors or commentaries.

\subsection{Information Sources and Search Strategy}

Our literature search was performed on 23 September 2021 on PubMed, Embase, Web of Science, and Cochrane Library. Our search terms were "tranexamic acid", "anterior cruciate ligament", "reconstruction" and "randomized trial". While performing the search, we had no active filters neither did we impose specific time periods.

\subsection{Selection Process}

The study selection was carried out by authors H.H. and M.L.M. through an independent screening of the eligibility criteria. All data were recorded independently, and in case of disagreement between the two authors, we had author R.P. intervening and helping them reach a common conclusion. The search terms were applied to study titles and all duplicates between different databases were removed. Furthermore, eligibility was determined by applying the criteria after reading the full text of the remaining articles.

\subsection{Data Collection Process}

Data collection was performed independently by two authors via a previously created spreadsheet. They extracted information such as: name of the first author, year of publication, study type, lot size, TXA protocol, type of used graft, drain usage, outcome measures, and follow-up duration.

\subsection{Outcomes}

We identified data for primary outcomes such as the knee function with the Lysholm score [21], IKDC score [22,23], pain levels with the visual-analog scale (VAS) [24], and the necessity of knee aspiration during the postoperative period. Where seen, we have also identified secondary outcomes such as TXA injection modality (intraarticular or intravenous), hemarthrosis severity (described by Coupens and Yates) [25], knee circumference, and drainage volume.

\subsection{Bias Assessment}

To evaluate bias risk, we applied the method described by Sterne et al. in 2019 [26]. They have revised the risk of bias tool (RoB), initially used widely in Cochrane or other systematic reviews [27]. This tool measures the risk of bias by analyzing data such as 
randomization, missing result data, measurement of outcomes or drift from intended interventions. In addition, it allows for researchers to rate the risk of bias as "low", "some concerns", or "high". Graphical depiction was realized with the aid of the Robvis platform [28].

\section{Results}

\subsection{Study Selection}

Our initial database search revealed 70 total results. Removing the 30 duplicates left us with 40 papers that would go into the screening process. After going through the screening process manually and applying the inclusion criteria, we were left with a total of six RCTs to analyze $[14,15,29-32]$. The identification, screening, and inclusion steps are all depicted in the PRISMA diagram (Figure 1).

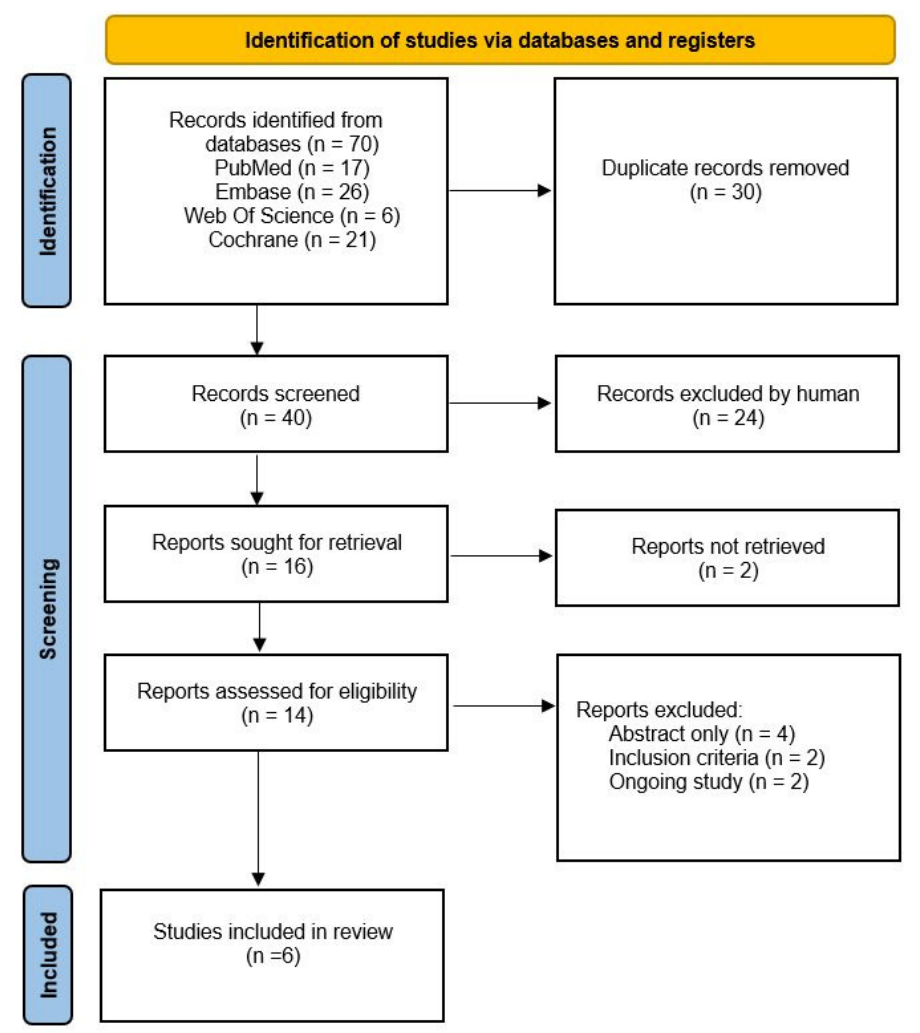

Figure 1. Search strategy and study screening using the PRISMA flow diagram.

\subsection{Study Characteristics}

The studies included in this review were published between 2015 and 2021. The selected studies included a total of 699 randomized patients. There were 362 TXA receiving patients while there were 337 control group patients. The mean age of the patients was 29 years, excluding the study of Banca et al., who did not report any kind of demographics (age, sex) for their lot. The follow-up duration ranged from 4 weeks to 12 weeks. Banca et al. split up the lot into 3 subgroups, thus ending up with a TXA lot size of $1 / 3$ of all patients and a control group of $1 / 3$ of all patients. The other group had received treatment with epsilon-minocaproic acid - an enzymatic inhibitor regarding residue such as plasmin (ensuring fibrinolysis). Another study with certain particularity regarding lot division was the one of Ma et al., who compared three equal groups-control, intravenous (IV) TXA, and intraarticular (IA) TXA. All patients had arthroscopic ACLR with hamstring grafts. Four studies reported the use of suction drains removed $24 \mathrm{~h}$ after the surgery. All studies reported postoperative pain (VAS) and evaluated articular effusion according to Coupens and Yates (CY). Baseline characteristics of all included studies can be found in Table 1. 
Table 1. Baseline characteristics and demographics of all included studies.

\begin{tabular}{|c|c|c|c|c|c|c|c|c|c|c|c|}
\hline \multirow{2}{*}{$\begin{array}{l}\text { First } \\
\text { Author, } \\
\text { Year }\end{array}$} & \multirow{2}{*}{$\begin{array}{c}\text { Sample } \\
\text { Size }\end{array}$} & \multicolumn{3}{|c|}{ Age, Mean \pm SD, y } & \multicolumn{3}{|c|}{ Sex, M/F } & \multicolumn{3}{|c|}{ Surgery Duration, Min } & \multirow{2}{*}{$\begin{array}{c}\text { Follow- } \\
\text { Up }\end{array}$} \\
\hline & & \multicolumn{2}{|c|}{ TXA } & Control & \multicolumn{2}{|c|}{ TXA } & Control & \multicolumn{2}{|c|}{ TXA } & Control & \\
\hline $\begin{array}{l}\text { Karaaslan, } \\
2015\end{array}$ & 105 & \multicolumn{2}{|c|}{$28.23 \pm 6.59$} & $28.31 \pm 9.01$ & \multicolumn{2}{|c|}{$51 / 2$} & $49 / 3$ & \multicolumn{2}{|c|}{$40 \pm 18$} & $45 \pm 15$ & 4 weeks \\
\hline Felli, 2019 & 80 & \multicolumn{2}{|c|}{$30.7 \pm 11.0$} & $32.0 \pm 10.5$ & \multicolumn{2}{|c|}{$27 / 13$} & $36 / 4$ & \multicolumn{2}{|c|}{$45 \pm 6.6$} & $40.8 \pm 12.8$ & 12 weeks \\
\hline $\begin{array}{c}\text { Chiang, } \\
2019\end{array}$ & 304 & \multicolumn{2}{|c|}{$25.7 \pm 8.4$} & $27.6 \pm 6.9$ & \multicolumn{2}{|c|}{$125 / 26$} & $119 / 30$ & \multicolumn{2}{|c|}{$54.5 \pm 17.2$} & $50.3 \pm 19.3$ & 4 weeks \\
\hline Lee, 2020 & 47 & \multicolumn{2}{|c|}{$30.3 \pm 9.0$} & $25.1 \pm 8.1$ & \multicolumn{2}{|c|}{$20 / 3$} & $21 / 3$ & \multicolumn{2}{|c|}{ NR } & NR & 6 weeks \\
\hline $\begin{array}{l}\text { Banca, } \\
2021\end{array}$ & 43 & \multicolumn{2}{|c|}{ NR } & NR & \multicolumn{2}{|c|}{ NR } & NR & \multicolumn{2}{|c|}{ NR } & NR & 4 weeks \\
\hline \multirow{2}{*}{ Ma, 2021} & \multirow{2}{*}{120} & IV & IA & \multirow{2}{*}{$30.1 \pm 7.7$} & IV & IA & \multirow{2}{*}{$23 / 17$} & IV & IA & \multirow[b]{2}{*}{$74.4 \pm 11.8$} & \multirow[b]{2}{*}{4 weeks } \\
\hline & & $32.7 \pm 8.5$ & $30.3 \pm 8.0$ & & $25 / 15$ & $26 / 14$ & & $76.5 \pm 11$ & $71.3 \pm 10.1$ & & \\
\hline
\end{tabular}

NR, not reported; IV, intravenous administration; IA, intraarticular administration.

\subsection{Risk of Bias and Data Quality}

The assessment of bias risk is summarized in Figures 2 and 3 for all the included studies. The overall quality of the studies regarding bias risk is considered high. Overall, most studies aimed at minimizing selection bias with the aid of software allocation, with only one study having had the allocation made by a researcher. Bias due to deviations from intended intervention has some concerns in three of the studies. We concluded that two studies have some concerns regarding missing outcome data, outcome measurement, and selection of the reported results.

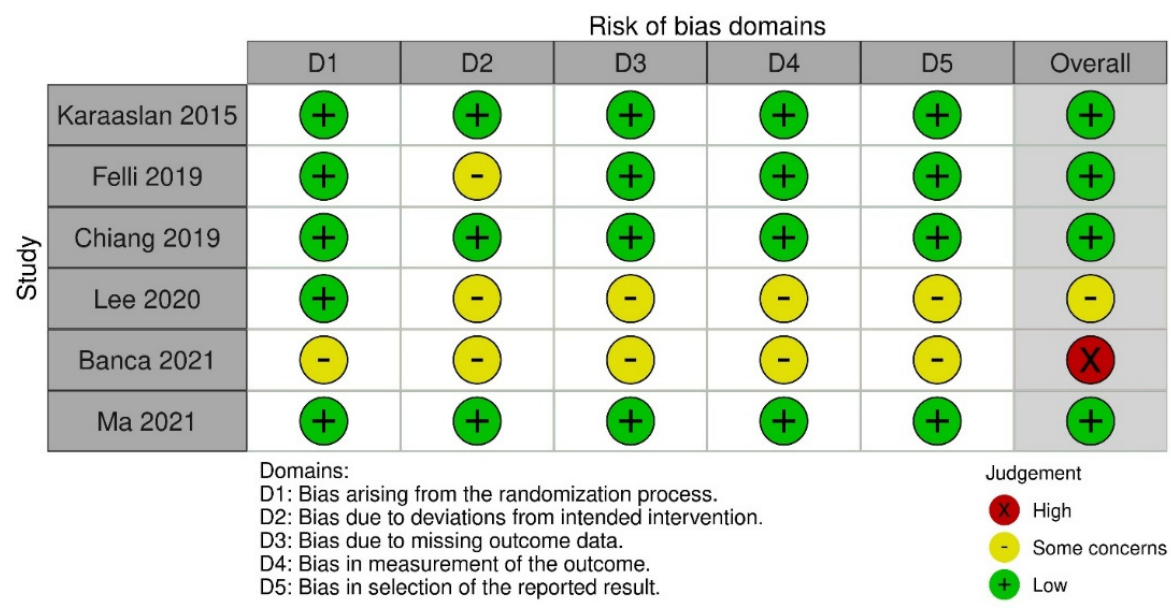

Figure 2. Assessment of risk of bias in the RCTs with the aid of the RoB tool, for individual domains and individual RCTs.

Bias arising from the randomization process Bias due to deviations from intended interventions

Bias due to missing outcome data Bias in measurement of the outcome Bias in selection of the reported result Overall risk of bias

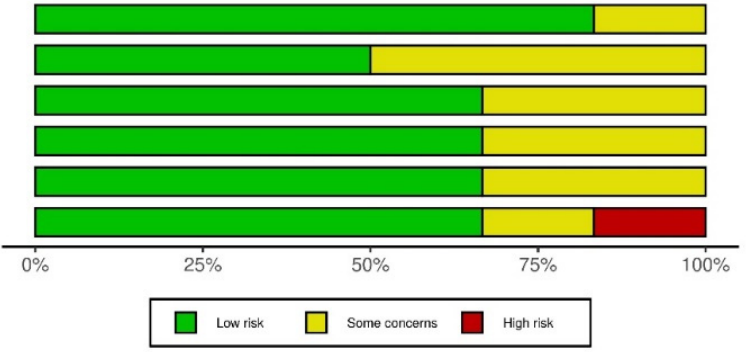

Figure 3. Summary assessment of bias of the included RCTs.

\subsection{Outcome Results}

Reported outcomes, TXA protocol, surgical protocol, and postoperative protocol were all synthesized in Table 2 for all our included studies. 
Table 2. Study design characteristics of all included studies.

\begin{tabular}{|c|c|c|c|c|c|c|}
\hline First Author, Year & \multicolumn{2}{|c|}{ TXA Protocol } & Type of Graft & Drain Usage & Outcome Measures & Postoperative Protocol \\
\hline \multirow{2}{*}{ Karaaslan, 2015} & \multicolumn{2}{|c|}{$\begin{array}{l}\text { Experimental: IV } 15 \mathrm{mg} / \mathrm{kg} 10 \mathrm{~min} \text { before tourniquet inflation, IV } \\
\text { infusion of } 10 \mathrm{mg} / \mathrm{kg} / \mathrm{h} \text { for } 3 \mathrm{~h} \text { after operation. }\end{array}$} & \multirow{2}{*}{ Hamstring } & \multirow{2}{*}{$\begin{array}{l}\text { Suction drain } \\
24 \mathrm{~h}\end{array}$} & \multirow{2}{*}{ CY, VAS, ROM } & \multirow{2}{*}{$\begin{array}{l}\text { Analgesia: tramadol Hcl } 100 \mathrm{mg} \text {, twice daily, acetaminophen at discharge } \\
\text { Rehab: compression bandage and Cryo-cuff. Continuous passive ROM } \\
12 \mathrm{~h} \text { postop. No ACL brace. WBAT. }\end{array}$} \\
\hline & Control: IV & ine placebo & & & & \\
\hline \multirow{2}{*}{ Felli, 2019} & \multicolumn{2}{|c|}{ Experimental: IV $15 \mathrm{mg} / \mathrm{kg} 10 \mathrm{~min}$ before tourniquet inflation. } & \multirow{2}{*}{ Hamstring } & \multirow{2}{*}{$\begin{array}{l}\text { Suction drain } \\
24 \mathrm{~h}\end{array}$} & \multirow{2}{*}{$\begin{array}{l}\text { blood amount drained, knee } \\
\text { circumference, ROM, VAS, CY, } \\
\text { quad strength, IKDC, Lysholm }\end{array}$} & \multirow{2}{*}{$\begin{array}{c}\text { Analgesia: ketorolac } 30 \mathrm{mg} / 8 \mathrm{~h} \text { first day, dexibuprofen } 400 \mathrm{mg} \text { for the } \\
\text { next } 5 \text { days } \\
\text { Rehab: active and passive ROM from PD2, } 90^{\circ} \text { mobility long knee brace } \\
30 \text { days. PWB } 3 \text { weeks. }\end{array}$} \\
\hline & Control: same vo & ne saline placebo & & & & \\
\hline \multirow{2}{*}{ Chiang, 2019} & \multicolumn{2}{|c|}{ Experimental: IA $10 \mathrm{~mL}$ TXA. } & \multirow{2}{*}{ Hamstring } & \multirow{2}{*}{$\begin{array}{l}\text { Suction drain } \\
\quad 24 \mathrm{~h}\end{array}$} & \multirow{2}{*}{ CY, ROM, IKDC, VAS } & \multirow{2}{*}{$\begin{array}{l}\text { Analgesia: NR } \\
\text { Rehab: WBAT. } 30^{\circ} \text { ROM for } 2 \text { weeks. } 120^{\circ} \text { ROM at } 4 \text { weeks. }\end{array}$} \\
\hline & Control: d & ot receive & & & & \\
\hline \multirow{2}{*}{ Lee, 2020} & Experimental: IA $30 \mathrm{mg} / \mathrm{mL}$ of & A in $100 \mathrm{~mL}$ saline after surgery. & \multirow{2}{*}{ Hamstring } & \multirow{2}{*}{ No drain } & \multirow{2}{*}{$\begin{array}{l}\text { blood loss, VAS, knee } \\
\text { circumference, ROM, Lysholm }\end{array}$} & $\begin{array}{l}\text { Analgesia: nefopam Hcl IV PD1, acetaminophen } 325 \mathrm{mg}+\text { tramadol Hcl } \\
37.5 \mathrm{mg} \text { PD5. }\end{array}$ \\
\hline & Control: d & ot receive & & & & $\begin{array}{c}\text { Rehab: compression stocking and air cuff. ROM and quad isometry PD1. } \\
\text { Gait and balance weeks 3-4. PWB weeks 6-8. }\end{array}$ \\
\hline Banca, 2021 & $\begin{array}{l}\text { Experimental: IV } 10 \mathrm{mg} / \mathrm{kg} \\
\text { TXA during anesthesia, IV } \\
\text { infusion of } 10 \mathrm{mg} / \mathrm{kg} / \mathrm{h} \text { for } 3 \mathrm{~h} \\
\text { after initial dose }\end{array}$ & $\begin{array}{l}\text { Experimental: } 100 \mathrm{mg} / \mathrm{kg} \text { in } \\
250 \mathrm{~mL} \text { saline of minocaproic } \\
\text { acid during anesthesia, IV } \\
\text { infusion of } 1 \mathrm{~g} / \mathrm{h} \text { for } 2 \mathrm{~h} \text { after } \\
\text { initial dose }\end{array}$ & Hamstring & No drain & VAS, CY, ROM, Lysholm & $\begin{array}{l}\text { Analgesia: NR } \\
\text { Rehab: NR }\end{array}$ \\
\hline \multirow[t]{2}{*}{ Ma, 2021} & $\begin{array}{l}\text { Experimental: IV } 15 \mathrm{mg} / \mathrm{kg} \\
\text { TXA in } 100 \mathrm{~mL} \text { saline, } 10 \mathrm{~min} \\
\text { before tourniquet release }\end{array}$ & $\begin{array}{l}\text { Experimental: IA } 15 \mathrm{mg} / \mathrm{kg} \\
\text { TXA in } 100 \mathrm{~mL} \text { saline, via } \\
\text { drainage tube }\end{array}$ & \multirow[t]{2}{*}{ Hamstring } & \multirow{2}{*}{$\begin{array}{l}\text { Suction drain } \\
\quad 24 \mathrm{~h}\end{array}$} & \multirow{2}{*}{$\begin{array}{l}\text { VAS, knee circumference, CY, } \\
\text { Lysholm }\end{array}$} & \multirow{2}{*}{$\begin{array}{l}\text { Analgesia: ketorolac } 30 \mathrm{mg} / 8 \mathrm{~h} \text { PD1, celecoxib } 200 \mathrm{mg} / 12 \mathrm{~h} \text { PD5 } \\
\text { Rehab: locked full extension knee brace. PWB. Full ROM week } 4 .\end{array}$} \\
\hline & Control: $100 \mathrm{~m}$ & line IV and IA & & & & \\
\hline
\end{tabular}

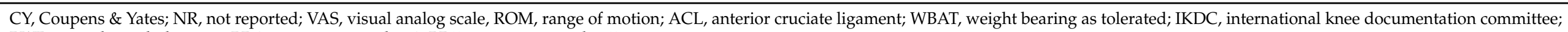

PWB, partial weight bearing; PD1, postoperative day 1; PD5, postoperative day 5. 
Estimated blood loss/drain output was measured in 4 of the 5 studies, resulting in a total pool of 196 patients with TXA administration in one way or another $[14,15,29,30]$. TXA was administered IV in three of these studies and IA in the remaining one $[14,29,30]$. These authors reported decreases in drain output between the TXA and control group of $90 \mathrm{~mL}(p<0.001), 74 \mathrm{~mL}(p<0.001)$, and $41.6 \mathrm{~mL} / 56.8 \mathrm{~mL}(p<0.001)$, all being considered statistically significant data. The only study that did not find statistical significance was the study of Lee et al., which performed IA TXA, but they measured the amount of blood loss, not the drain output.

The necessity for knee aspiration was reported by Felli et al. and Chiang et al. [30,31] The first reported aspiration in three patients from the control group, but with no statistical significance. Chiang et al. reported that no knee aspirations were needed.

Postoperative pain levels (VAS) were measured as either primary or secondary outcomes in all the included studies. Statistical significance regarding a lower VAS in the intervention groups was mostly reported for the early postoperative period (two weeks) [14, $29,31,32]$. When cross-checking the analgesic protocol of these studies, there seems to be no correlation with the decrease in VAS. There are some studies that show no statistical significance in any of the follow-ups such as the ones of Lee and Felli [14,30].

The hemarthrosis grade was an outcome that was measured and noted in 5 of our 6 included studies (Table 3). This was graded in accordance with the system designed by Coupens and Yates (CY) in 1991 [25]. They classify the gravity of the hematoma in five stages according to clinical signs. A statistically significant decrease was reported for the first two weeks in three studies [14,29,31], and after two weeks or more in one study [30].

Knee ROM was reported in five studies at multiple follow-up visits ranging from postoperative day 1 (PD1) to postoperative week 12 [15,29-32]. None of the studies showed any statistically significant improvement regarding ROM, no matter what rehabilitation protocol was used.

Knee circumference was reported as outcome in three studies [14,15,30]. Felli et al. and $\mathrm{Me}$ et al. at measured the circumference $1 \mathrm{~cm}$ proximal to the superior pole of the patella, while Lee et al. measured it at the transverse axis of the patellar center. This outcome was reported as statistically significant only by Ma et al. both at the 1- and 2-week follow-ups.

Functional scores such as Lysholm and IKDC were reported as secondary postoperative outcomes in 4 of the 6 studies [14,30-32]. Felli et al. reported the Lysholm score at 4 weeks and 12 weeks, without any statistical significance. Banca et al. reported the Lysholm score at two weeks with statistical significance. Ma et al. reported the Lysholm score at four weeks and found no statistical significance. IKDC was reported by Felli et al. at 4 and 12 weeks, and Chiang et al. at four weeks, without any statistical significance. 
Table 3. Hemarthrosis grade with the aid of the Coupens and Yates grading system for all included studies.

\begin{tabular}{|c|c|c|c|c|c|c|c|c|c|c|}
\hline \multirow{2}{*}{ First Author, Year } & \multicolumn{2}{|c|}{ CY PD 1-5 (0/1/2/3/4) } & \multicolumn{2}{|c|}{ CY Week 1 (0/1/2/3/4) } & \multicolumn{2}{|c|}{ CY Week $2(0 / 1 / 2 / 3 / 4)$} & \multicolumn{2}{|c|}{ CY Week 4 (0/1/2/3/4) } & \multicolumn{2}{|c|}{ CY 3 Mo $(0 / 1 / 2 / 3 / 4)$} \\
\hline & TXA & Control & TXA & Control & TXA & Control & TXA & Control & TXA & Control \\
\hline Karaaslan, 2015 & - & - & $15 / 24 / 8 / 5 / 1^{*}$ & $0 / 6 / 12 / 16 / 18$ & $20 / 29 / 3 / 1 / 0^{*}$ & $3 / 24 / 19 / 6 / 0$ & - & - & - & - \\
\hline Felli, 2019 & 1.6 & 2.1 & 2.1 & 2.8 & $1.5^{*}$ & 2.3 & 0.8 & $1.0(0.7$ to 1.3$)$ & 0.3 & 0.2 \\
\hline Lee, 2020 & - & - & - & - & - & - & - & - & - & - \\
\hline Banca, 2021 & - & - & - & - & - & - & - & - & - & - \\
\hline Ma, 2021 & - & - & $\begin{array}{l}9 / 16 / 8 / 5 / 2^{*} \\
8 / 16 / 11 / 4 / 1^{*}\end{array}$ & $0 / 5 / 11 / 15 / 9$ & $\begin{array}{l}13 / 19 / 6 / 2 / 0^{*} \\
13 / 18 / 8 / 1 / 0^{*}\end{array}$ & $4 / 16 / 16 / 4 / 0$ & $\begin{array}{l}16 / 17 / 5 / 2 / 0 \\
18 / 17 / 2 / 3 / 0\end{array}$ & $11 / 18 / 8 / 3 / 0$ & - & - \\
\hline
\end{tabular}

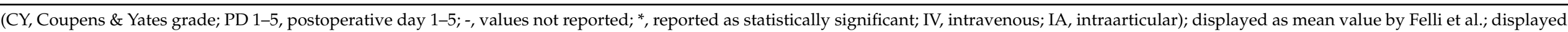
separately for both intervention groups by Ma et al. 


\section{Discussion}

The common use of TXA in arthroscopies is beginning to gain traction, after it has already become widespread in arthroplasties and trauma. We believe that this subject is yet to be fully investigated. This is also proven by the small amount of good quality studies that can be found, and the small lot sizes they have. Having a reduced amount of data regarding a specific subject makes it very hard to define a certain degree of heterogeneity. This is caused by a high diversity of TXA administration protocols, a high diversity of analgesia options, a wide variety of rehab protocols and a multitude of outcome measures that can be defined. High heterogeneity is one of the reasons that can justify the low quality of meta-analyses that are currently published.

When talking about the different TXA administration protocol, we can see two main ideas: IV and IA. Out of six studies, we saw three of them having an exclusively IV protocol, and a 4th one having two intervention groups-one IV and one IA. Current literature facts indicate that most authors would prefer IV administration protocols over IA. This may be caused by the speculations that IA TXA can affect chondrocytes, as it was proven in an in-vitro study $[33,34]$. On the other hand, the authors showed that the cytotoxicity is related to the dosage of TXA, so further studies may be needed to determine a certain threshold that provides a sufficient benefit while not proving toxicity. Furthermore, recent studies [35] have also shown that topical use of TXA also reduces surgical blood loss and the need for blood transfusions during knee and hip arthroplasty while not increasing the risk for notable adverse events such as stroke or thromboembolism [36]. Our study failed to show a clear benefit for any one of the administration methods (IV vs. IA).

Improving the postoperative life quality through lower pain levels and better function has been the main motivation behind using TXA in ACLR. We know that pain levels may be controlled either through analgesia or decreased intraarticular pressure that may be caused by postoperative hemarthrosis. Increased hemarthrosis can cause high levels of postoperative pain, infection rates, or cartilage damage [37]. Our systematic review shows a consistent association between TXA patients and decreased pain levels (VAS). Other reviews and meta-analyses have also found that the intraoperative and perioperative use of TXA in arthroscopic surgery decreases hemarthrosis volumes [13,38,39]. An important point of discussion here can be developed regarding the clinical significance of the drain outputs, as negative pressure drains tend to maintain bleeding. Some may consider the hemarthrosis level to be more significant, considering that drainage would not be used. Once low or moderate hemarthrosis occurs, the necessity for joint aspiration is paramount to reducing knee pain, joint effusion, intraarticular adhesion, and infection rates [40]. Another negative aspect of hemarthrosis is that it can cause decreased joint function and muscle strength due to a secondary deficit of rehabilitation caused by local pain.

Analyzing the results of pain levels proved much more consistent (Table 4). All studies used the same measurable outcome, and all of them seem to have a common follow-up trend in the 1- and 2-week check-ups. This allowed for decreased variability in outcomes and the results regarding this matter can be considered "high quality" scientific data. Studies showed a consistent decrease in pain levels of the TXA groups compared to the control groups after 1 and 2 weeks respectively, while not indicating improvement in the first $3-5$ days of the postoperative period. Comparing between the two methods of TXA administration, we found no significant differences in VAS scores. When looking at longer timeframes (2-3 months follow-up), we can see that VAS levels tend to equalize between TXA and control groups, indicating that the intervention has short-term benefits. 
Table 4. VAS outcome values for all included studies for all recorded follow-up.

\begin{tabular}{|c|c|c|c|c|c|c|c|c|c|c|c|c|c|c|}
\hline \multirow{2}{*}{$\begin{array}{l}\text { First Author, } \\
\text { Year }\end{array}$} & \multicolumn{2}{|c|}{ VAS Score PD 1-5 } & \multicolumn{2}{|c|}{ VAS Score Week 1} & \multicolumn{2}{|c|}{ VAS Score Week 2} & \multicolumn{2}{|c|}{ VAS Score Week 3} & \multicolumn{2}{|c|}{ VAS Score 1 Mo } & \multicolumn{2}{|c|}{ VAS Score 2 Mo } & \multicolumn{2}{|c|}{ VAS Score 3 Mo } \\
\hline & TXA & Control & TXA & Control & TXA & Control & TXA & Control & TXA & Control & TXA & Control & TXA & Control \\
\hline $\begin{array}{l}\text { Karaaslan, } \\
2015\end{array}$ & $1.4^{*}(1$ to 5$)$ & 2.9 (2 to 5$)$ & - & - & $2 *(1$ to 4$)$ & $4(2$ to 5$)$ & $2 *(1$ to 4$)$ & $3(1$ to 4$)$ & - & - & - & - & - & - \\
\hline Felli, 2019 & 2 (1.1 to 2.9$)$ & 1.8 (1 to 2.6$)$ & $\begin{array}{c}0.4(-0.3 \text { to } \\
1.1)\end{array}$ & $\begin{array}{c}1.1(0.1 \text { to } \\
2.1)\end{array}$ & $\begin{array}{c}-1.7(-2.4 \\
\text { to } 1)\end{array}$ & $\begin{array}{c}-0.1(-1.0 \\
\text { to } 0.8)\end{array}$ & - & - & $\begin{array}{c}-1.6(-2.5 \\
\text { to }-0.7)\end{array}$ & $\begin{array}{c}-1.1(-1.9 \\
\text { to }-0.3)\end{array}$ & - & - & $\begin{array}{c}-2.5(-3.5 \\
\text { to }-1.5)\end{array}$ & $\begin{array}{c}-2.4(-3.2 \\
\text { to }-1.6)\end{array}$ \\
\hline $\begin{array}{l}\text { Chiang, } \\
2019\end{array}$ & $3.2 *$ & 6.7 & - & - & - & - & - & - & 1.7 & 2.0 & - & - & - & - \\
\hline Lee, 2020 & $\begin{array}{l}4.2 \\
3.3 \\
3.0 \\
2.9 \\
2.0\end{array}$ & $\begin{array}{l}3.3 \\
3.1 \\
2.6 \\
2.3 \\
2.1\end{array}$ & - & - & - & - & - & - & - & - & - & - & - & - \\
\hline Banca, 2021 & - & - & $-*$ & - & - & - & - & - & - & - & - & - & - & - \\
\hline Ma, 2021 & - & - & $2.55 *$ & 3.5 & $2.25^{*}$ & 3.1 & - & - & 1.7 & 1.9 & - & - & - & - \\
\hline
\end{tabular}

$\left(-\right.$, values not reported; ${ }^{*}$, reported as statistically significant); displayed as mean value for Ma et al. for both intervention groups (IV and IA). 
One thing that needs to be addressed regarding pain management is again the differences in postoperative pain management protocols. All our included studies have had different pain management protocols: associations of Tramadol and non-steroidal antiinflammatory drugs (NSAIDs), Ketorolac $(30 \mathrm{mg} / 8 \mathrm{~h}$ ) for the first day and dexibuprofen ( $400 \mathrm{mg} / 12 \mathrm{~h}$ ) in the next five days, Ketorolac $(30 \mathrm{mg} / 8 \mathrm{~h}$ ) for the first day and celecoxib $(200 \mathrm{mg} / 12 \mathrm{~h}$ ) for the next five days, Acupan for the first two days and acetaminophen $325 \mathrm{mg}$ and tramadol hydrochloride $37.5 \mathrm{mg}$ for the next three days. Having differences in the pain management protocol may influence the significance of the VAS assessments. Thus, it is advisable to account for the VAS values only as secondary outcomes for studies, as pain management standardization will be hard to achieve.

Functional scores give us a standardized method of evaluating the patient's daily activities, and how their pathology influences them. Specifically for evaluating the function of the knee, our selected studies have defined as measured outcomes the IKDC (international knee documentation committee) scale and the Lysholm scoring system [21,22]. Only two of our studies have reported Lysholm scores at the same follow-up (one month) so drawing any conclusions based solely on this information would not be valid. The nature of the included studies meant that most outcome variables were based on early postoperative clinical information such as pain and hemarthrosis grade, more than on functional scores calculated with the aid of a questionnaire. From a functional point of view, we still need to wait for more specific studies to be published aimed exactly at evaluating knee function.

Our review has several limitations. TXA can be administered in multiple ways, and this results in low data heterogeneity. In other words, we encountered difficulties when trying to pool all the existent data regarding TXA administration. Future RCTs should focus on a homogenous administration protocol. Having the same outcome measure being recorded in different studies at different points in time impedes the process of statistical analysis. Except one RCT that had a sample size of 300 patients, all the other studies showed small lots of patients, thus decreasing the statistical power of their evidence. We have hade common outcome measures throughout the RCTs but the primary outcomes for the studies varied. This has, in turn, led to big differences regarding study conceptualization, follow-up visits, and reporting outcomes. The low number of RCTs included is again a big limitation of our review, and we probably need more data on this subject.

\section{Conclusions}

In our study, we show that TXE use in arthroscopic ACLR decreases early postoperative blood loss and pain. This results in reduced hemarthrosis and knee aspiration incidence. Some evidence of improvement in functional scores was observed, but we believe that this needs to be addressed in specific long-term result studies. Due to insufficient evidence, it remains to be seen which one of the administration protocols (IV/IA) should be used as the standard.

Author Contributions: Conceptualization, R.P.; methodology, M.L.M.; software, A.B. and M.A.Q.; validation, B.D. and D.M.; writing—original draft preparation, M.L.M.; writing—review and editing, M.L.M. and D.M.; supervision, R.P. and B.D.; funding acquisition, R.P. All authors have read and agreed to the published version of the manuscript.

Funding: This research received no external funding. The APC was funded by "Victor Babes" University of Medicine and Pharmacy.

Institutional Review Board Statement: Not applicable.

Informed Consent Statement: Not applicable.

Conflicts of Interest: The authors declare no conflict of interest. The funders had no role in the design of the study; in the collection, analyses, or interpretation of data; in the writing of the manuscript, or in the decision to publish the results. 


\section{References}

1. Molina, C.S.; Thakore, R.V.; Blumer, A.; Obremskey, W.T.; Sethi, M.K. Use of the National Surgical Quality Improvement Program in orthopaedic surgery. Clin. Orthop. Relat. Res. 2015, 473, 1574-1581. [CrossRef] [PubMed]

2. Lyman, S.; Koulouvaris, P.; Sherman, S.; Do, H.; Mandl, L.A.; Marx, R.G. Epidemiology of anterior cruciate ligament reconstruction: Trends, readmissions, and subsequent knee surgery. J. Bone Jt. Surg. Am. 2009, 91, 2321-2328. [CrossRef] [PubMed]

3. Treuting, R. Minimally invasive orthopedic surgery: Arthroscopy. Ochsner J. 2000, 2, 158-163. [PubMed]

4. Hurley, E.T.; Manjunath, A.K.; Strauss, E.J.; Jazrawi, L.M.; Alaia, M.J. Return to play after anterior cruciate ligament reconstruction with extra-articular augmentation: A systematic review. Arthroscopy 2021, 37, 381-387. [CrossRef] [PubMed]

5. Allum, R. Complications of arthroscopic reconstruction of the anterior cruciate ligament. J. Bone Jt. Surg. Br. 2003, 85, 12-16. [CrossRef] [PubMed]

6. Painter, T.W.; McIlroy, D.; Myles, P.S.; Leslie, K. A survey of anaesthetists' use of tranexamic acid in noncardiac surgery. Anaesth Intensive Care 2019, 47, 76-84. [CrossRef] [PubMed]

7. Ng, W.; Jerath, A.; Wąsowicz, M. Tranexamic acid: A clinical review. Anaesthesiol. Intensive Ther. 2015, 47, 339-350. [CrossRef] [PubMed]

8. Okamoto, S.; Okamoto, U. Amino-methyl-cyclohexanecarboxylic acid: AMCHA. Keio J. Med. 1962, 11, 105-115. [CrossRef]

9. Kagoma, Y.K.; Crowther, M.A.; Douketis, J.; Bhandari, M.; Eikelboom, J.; Lim, W. Use of antifibrinolytic therapy to reduce transfusion in patients undergoing orthopedic surgery: A systematic review of randomized trials. Thromb. Res. 2009, 123, 687-696. [CrossRef] [PubMed]

10. Lin, Z.X.; Woolf, S.K. Safety, efficacy, and cost-effectiveness of tranexamic acid in orthopedic surgery. Orthopedics 2016, 39, 119-130. [CrossRef] [PubMed]

11. Henry, D.A.; Carless, P.A.; Moxey, A.J.; O'Connell, D.; Stokes, B.J.; Fergusson, D.A.; Ker, K. Anti-fibrinolytic use for minimising perioperative allogeneic blood transfusion. Cochrane Database Syst. Rev. 2011, 16, CD001886. [CrossRef] [PubMed]

12. Ishida, K.; Tsumura, N.; Kitagawa, A.; Hamamura, S.; Fukuda, K.; Dogaki, Y.; Kubo, S.; Matsumoto, T.; Matsushita, T.; Chin, T.; et al. Intra-articular injection of tranexamic acid reduces not only blood loss but also knee joint swelling after total knee arthroplasty. Int. Orthop. 2011, 35, 1639-1645. [CrossRef]

13. Belk, J.W.; McCarty, E.C.; Houck, D.A.; Dragoo, J.L.; Savoie, F.H.; Thon, S.G. Tranexamic acid use in knee and shoulder arthroscopy leads to improved outcomes and fewer hemarthrosis-related complications: A systematic review of level I and II studies. Arthroscopy 2021, 37, 1323-1333. [CrossRef]

14. Ma, R.; Wu, M.; Li, Y.; Wang, J.; Wang, W.; Yang, P.; Wang, K. The comparative efficacies of intravenous administration and intraarticular injection of tranexamic acid during anterior cruciate ligament reconstruction for reducing postoperative hemarthrosis: $\mathrm{A}$ prospective randomized study. BMC Musculoskelet Disord. 2021, 22, 114. [CrossRef] [PubMed]

15. Lee, J.W.; Kim, S.G.; Kim, S.H.; Cho, H.W.; Bae, J.H. Intra-articular administration of tranexamic acid has no effect in reducing intra-articular hemarthrosis and postoperative pain after primary ACL reconstruction using a quadruple hamstring graft: A randomized controlled trial. Orthop. J. Sports Med. 2020, 22, 8. [CrossRef]

16. Fried, J.W.; Bloom, D.A.; Hurley, E.T.; Baron, S.L.; Popovic, J.; Campbell, K.A.; Strauss, E.J.; Jazrawi, L.M.; Alaia, M.J. Tranexamic acid has no effect on postoperative hemarthrosis or pain control after anterior cruciate ligament reconstruction using bone-patellar tendon-bone autograft: A double-blind, randomized, controlled trial. Arthroscopy 2021, 37, 1883-1889. [CrossRef] [PubMed]

17. Ishibashi, Y.; Adachi, N.; Koga, H.; Kondo, E.; Kuroda, R.; Mae, T.; Uchio, Y. Japanese Orthopaedic Association (JOA) clinical practice guidelines on the management of anterior cruciate ligament injury-Secondary publication. J. Orthop. Sci. 2020, 25, 6-45. [CrossRef] [PubMed]

18. American Academy of Orthopaedic Surgeons. Management of Anterior Cruciate Ligament Injuries Evidence-Based Clinical Practice Guideline. Available online: https:/ / www.aaos.org/globalassets / quality-and-practice-resources/anterior-cruciateligament-injuries/anterior-cruciate-ligament-injuries-clinical-practice-guideline-4-24-19.pdf (accessed on 28 September 2021).

19. Moher, D.; Liberati, A.; Tetzlaff, J.; Altman, D.G.; PRISMA Group. Preferred reporting items for systematic reviews and meta-analyses: The PRISMA statement. PLoS Med. 2009, 21, e1000097. [CrossRef] [PubMed]

20. Page, M.J.; Moher, D.; Bossuyt, P.M.; Boutron, I.; Hoffmann, T.C.; Mulrow, C.D.; Shamseer, L.; Tetzlaff, J.M.; Akl, E.A.; Brennan, S.E.; et al. PRISMA 2020 explanation and elaboration: Updated guidance and exemplars for reporting systematic reviews. BMJ 2021, 372, n160. [CrossRef] [PubMed]

21. Lysholm, J.; Gillquist, J. Evaluation of knee ligament surgery results with special emphasis on use of a scoring scale. Am. J. Sports Med. 1982, 10, 150-154. [CrossRef] [PubMed]

22. Collins, N.J.; Misra, D.; Felson, D.T.; Crossley, K.M.; Roos, E.M. Measures of knee function: International Knee Documentation Committee (IKDC) Subjective Knee Evaluation Form, Knee Injury and Osteoarthritis Outcome Score (KOOS), Knee Injury and Osteoarthritis Outcome Score Physical Function Short Form (KOOS-PS), Knee Outcome Survey Activities of Daily Living Scale (KOS-ADL), Lysholm Knee Scoring Scale, Oxford Knee Score (OKS), Western Ontario and McMaster Universities Osteoarthritis Index (WOMAC), Activity Rating Scale (ARS), and Tegner Activity Score (TAS). Arthritis Care Res. 2011, 63 (Suppl. S11), S208-S228.

23. Todor, A.; Vermesan, D.; Haragus, H.; Patrascu JMJr Timar, B.; Cosma, D.I. Cross-cultural adaptation and validation of the Romanian International Knee Documentation Committee-subjective knee form. PeerJ 2020, 3, e8448. [CrossRef] [PubMed]

24. Huskisson, E.C. Measurement of pain. Lancet 1974, 9, 1127-1131. [CrossRef] [PubMed] 
25. Coupens, S.D.; Yates, C.K. The effect of tourniquet use and hemovac drainage on postoperative hemarthrosis. Arthroscopy 1991, 7 , 278-282. [CrossRef] [PubMed]

26. Sterne, J.A.C.; Savović, J.; Page, M.J.; Elbers, R.G.; Blencowe, N.S.; Boutron, I.; Cates, C.J.; Cheng, H.Y.; Corbett, M.S.; Eldridge, S.M.; et al. RoB 2: A revised tool for assessing risk of bias in randomised trials. BMJ 2019, 366, 14898. [CrossRef] [PubMed]

27. Higgins, J.P.; Altman, D.G.; Gøtzsche, P.C.; Jüni, P.; Moher, D.; Oxman, A.D.; Savovic, J.; Schulz, K.F.; Weeks, L.; Sterne, J.A.; et al. The Cochrane Collaboration's tool for assessing risk of bias in randomised trials. BMJ 2011, 343, d5928. [CrossRef]

28. McGuinness, L.A.; Higgins, J.P.T. Risk-of-bias VISualization (robvis): An R package and Shiny web app for visualizing risk-of-bias assessments. Res. Synth. Methods 2021, 12, 55-61. [CrossRef] [PubMed]

29. Karaaslan, F.; Karaoğlu, S.; Yurdakul, E. Reducing intra-articular hemarthrosis after arthroscopic anterior cruciate ligament reconstruction by the administration of intravenous tranexamic acid: A prospective, randomized controlled trial. Am. J. Sports Med. 2015, 43, 2720-2726. [CrossRef] [PubMed]

30. Felli, L.; Revello, S.; Burastero, G.; Gatto, P.; Carletti, A.; Formica, M.; Alessio-Mazzola, M. Single intravenous administration of tranexamic acid in anterior cruciate ligament reconstruction to reduce postoperative hemarthrosis and increase functional outcomes in the early phase of postoperative rehabilitation: A randomized controlled trial. Arthroscopy 2019, 35, 149-157. [CrossRef] [PubMed]

31. Chiang, E.R.; Chen, K.H.; Wang, S.T.; Ma, H.L.; Chang, M.C.; Liu, C.L.; Chen, T.H. Intra-articular injection of tranexamic acid reduced postoperative hemarthrosis in arthroscopic anterior cruciate ligament reconstruction: A prospective randomized study. Arthroscopy 2019, 35, 2127-2132. [CrossRef] [PubMed]

32. Banca, V.L.; Suzuki Leal Roque, J.G.; Schimdt Navarro, M. Evaluation of antifibrinolytic use in anterior cruciate ligament arthroscopic reconstruction. A prospective clinical trial. Muscles Ligaments Tendons J. 2021, 11, 340-343. [CrossRef]

33. Parker, J.D.; Lim, K.S.; Kieser, D.C.; Woodfield, T.B.F.; Hooper, G.J. Is tranexamic acid toxic to articular cartilage when administered topically? What is the safe dose? Bone Jt. J. 2018, 100-B, 404-412. [CrossRef] [PubMed]

34. Kalina, R.; Fidler, E.; Béreš, M.; Zeman, P.; Sigmund, M.; Gallo, J. Efekt jednorázového podání kyseliny tranexamové při rekonstrukci předního zkřiženého vazu hamstringy: Randomizovaná klinická studie [Effect of a single dose of tranexamic acid administered during anterior cruciate ligament reconstruction using hamstrings: A randomized clinical study]. Acta Chir. Orthop. Traumatol. Cech. 2021, 88, 184-190. [PubMed]

35. Teoh, W.Y.; Tan, T.G.; Ng, K.T.; Ong, K.X.; Chan, X.L.; Tsan, S.E.H.; Wang, C.Y. Prophylactic topical tranexamic acid versus placebo in surgical patients: A systematic review and meta-analysis. Ann. Surg. 2020, 273, 676-683. [CrossRef]

36. Myers, S.P.; Kutcher, M.E.; Rosengart, M.R.; Sperry, J.L.; Peitzman, A.B.; Brown, J.B.; Neal, M.N. Tranexamic acid administration is associated with an increased risk of posttraumatic venous thromboembolism. J. Trauma Acute Care Surg. 2019, 86, 20-27. [CrossRef]

37. Small, N.C. Complications in arthroscopic surgery performed by experienced arthroscopists. Arthroscopy 1988, 4, $215-221$. [CrossRef]

38. Tan, T.K.; Ng, K.T.; Lim, H.J.; Radic, R. Effect of tranexamic acid in arthroscopic anterior cruciate ligament repair: A systematic review and meta-analysis of randomised clinical trials. J. Orthop. Surg. 2021, 29, 23094990211017352. [CrossRef] [PubMed]

39. Goldstein, K.; Jones, C.; Kay, J.; Shin, J.; Darren de Sa, M.D. Tranexamic Acid Administration in Arthroscopic Surgery Is a Safe Adjunct to Decrease Postoperative Pain and Swelling: A Systematic Review and Meta-Analysis. Arthroscopy 2021, 14. [CrossRef] [PubMed]

40. Ohdera, T.; Tokunaga, M.; Hiroshima, S.; Yoshimoto, E.; Matsuda, S. Recurrent hemarthrosis after knee joint arthroplasty: Etiology and treatment. J. Arthroplasty 2004, 19, 157-161. [CrossRef] 